$\xi=-10$

\title{
Management Information System for Monitoring and Inspection of the Implementation of Universities
}

\author{
Frits Gerit John Rupilele ${ }^{1}$, Irwan Soulisa ${ }^{1}$, Aram Palilu ${ }^{1}$, Abdurrozzaq Hasibuan ${ }^{2}$, Ontje Fransisca Winesty \\ Jamil $^{4}$, Mutiara Dara Utama ${ }^{5}$, Amelia Tahitu ${ }^{5}$, Ricardo Freedom Nanuru ${ }^{\text {* }}$ \\ ${ }^{1}$ Universitas Victory Sorong, Sorong, Indonesia \\ ${ }^{2}$ Faculty of Engineering, Universitas Islam Sumatera Utara, Medan, Indonesia \\ ${ }^{3}$ Universitas Halmahera, Tobelo, Indonesia \\ ${ }^{4}$ Universitas Khairun, Ternate, Indonesia \\ ${ }^{5}$ Universitas Kristen Indonesia Maluku, Ambon, Indonesia \\ *Corresponding author E-mail: ricardonanuru632@gmail.com
} Tutupary $^{3}$, Frets Alfret Goraph ${ }^{3}$, Herman Sidete ${ }^{3}$, Erland Mouw ${ }^{3}$, Selfianus Laritmas ${ }^{3}$, Simson Tondo ${ }^{3}$, Mohamad

\begin{abstract}
Inspection of Universities infringement (PT) is one of Controlling, Supervising and Guidance (dalwasbin) activities aimed at developing problematic universities in order to be back on track and able to run Tri Dharma of Higher Education in accordance with National Standard of Higher Education. Based on the results of evaluation and inspection of Higher Education in 2017 at Coordination of Private Higher Education Region XIV there found 29 Universities out of 61 Universities that committed violations. Management of infringement inspection of Higher Education requires the role of information technology due to the geographic area of the Higher Education and management of Higher Education inspection that is still manual causing management to be ineffective and inefficient. Coordination of Private Higher Education Region XIV requires an information system that can support and assist data of infringement in universities and management of universities inspection. The design of information system in this research used waterfall method. The design of system models used unified modeling language diagrams (UML) including use case diagrams and activity diagrams. The design of this information system generated a system that can support the management of integrated and centralized infringement inspection to facilitate the inspection, monitoring and reporting of inputs and information for Coordination of Private Higher Education and the ministry in mapping the institutional quality Higher Education.
\end{abstract}

Keywords: Information System, Waterfall, Unified Modeling Language, Coordination of Private Higher Education

\section{Introduction}

Universities as a unit of education that carries out higher education which executes the duties for the implementation of Tridarma of Higher Education by referring to the national standard of higher education (SN-Dikti), either educational standards, research standards, or community service standards as regulated in Minister of Research, Technology and Education No. 44 of 2015 on SNDikti. In practice, not a few higher education programs run by Universities that deviate from SN-Dikti.

The phenomenon of infringement against SN-Dikti can occur either on the infringement of graduates competency standard, content standard, learning process standard, educational assessment standard, education personnel standard, infrastructure standard, management standard, and education funding standard. Infringment against the SN-Dikti will eventuall generate graduates who are far from the expected competencies, whether involving cognitive, affective, or psychomotor aspects. Efforts to ensure that universities do not violate the implementation of higher education itself can be done through control, supervision and guidance activities (dalwasbin), whether conducted by the Ministry of Research and Technology of Higher Education through the Directorate General of Research and Technology Institution of
Higher Education and through the Higher Education Service Institution at the regional level.

Coordination of Private Higher Education is an institution established by the government to conduct guidance to private universities. The function of Coordination of Private Higher Education is to coordinate private universities to be able to carry out the Higher Education accountably in accordance with SNDikti [1]. Coordination of Private Higher Education Region XIV is one of Coordination of Private Higher Education in eastern Indonesia with the working area of Papua and West Papua Provinces. The duty of Coordination of Private Higher Education Region XIV is to implement dalwasbin against universities.

One of the activities of dalwasbin in Coordination of Private Higher Education Region XIV is monitoring and evaluating the activities conducted by the academic performance evaluation team (EKA Team). The duty of EKA Team is to conduct an infringement inspection to the Universities aiming to foster the problematic universities, in order to be back on track and able to run Tri Dharma of Higher Education in accordance with SN-Dikti, to guarantee the public in obtaining healthy choice of universities, as a place to study and to protect the society from malpractice higher education whcih is unhealthy, illegal, and disadvantageous, $\mathrm{s}$ well as to provide information and inputs to the Ministry in mapping the institutional quality of higher education. 
Coordination of Private Higher Education Region XIV of Papua and West Papua currently has 61 Universities. Based on the results of the evaluation of the implementation of Higher Education in 2017, 29 Universities are indicated in the infringement of the implementation of universities. The infringements found include lecturer deficiency in 14 universities, lecturer ratio in 13 universities, and reporting of Higher Education data fraud in 2 universities. The findings were then followed up by Coordination of Private Higher Education by conducting dalwasbin activities or monitoring and inspection against the universities.

The monitoring and inspection against the universiteis conducted by the EKA Team are based on data and information derived from reports/complaints of the society done in verbal/in writing, the results of monitoring and evaluation of Coordination of Private Higher Education, and mass media news. Procedures for investigation of alleged infringement of universities on Coordination of Private Higher Education Region XIV start from findings of alleged infringement at the universities, schedule determination, officer of Coordination of Private Higher Education and EKA Team, preparation of EKA Team document from letter of assignment to the report of inspection result covering Minutes of the Inspection and recommendation and administrative sanction. Determination of administrative sanctions on universities proven to committ infringement is based on the type of sanction stipulated in Regulation of Minister of Research and Technology of Higher Education Number 100 of 2016, article 25 , paragraph 2 on administrative sanctions consisting of mild, moderate and heavy administrative sanctions.

The obstacles of Coordination of Private Higher Education Region XIV in conducting monitoring and inspection of the implementation of universities are among others: 1) geographical factors of a vast university area and difficult or limited transportation networks, 2) management of monitoring activities including the management of alleged violation data of the universities, scheduling for inspection, preparation for inspector's documents up to the reports of monitoring results of universities which run inefficiently due to manual arrangement.

Coordination of Private Higher Education Region XIV of Papua and West Papua need a management information system (MIS) that can assist and manage the evaluation result of the implementation of universities and support the monitoring and inspectiom agains universities. MIS basically involves the process of collecting, processing, storing, retrieving and communicating relevant information for the purpose of efficient management operations and for business planning in the organization[2].

MIS design in this research applied waterfall method. This method is one of the methods of system development that is widely used because it has a systematic and sequential development approach. The design of MIS model used UML diagrams includes use case diagrams and activity diagrams.

MIS designed in this research is a web-based one that can run on various platforms and can be accessed anywhere so it becomes a solution to the problem of geographical location of universities which are scattered in the islands areas. This MIS produces a system that can support the management of monitoring and inspections on the integrated and centralized implementation of Higher Education so as to facilitate the monitoring activities and have a report on the implementation of the higher education which becomes the input and information for Coordination of Private Higher Education and the ministry in mapping the quality of institutional Higher education.

Some related research on the importance of MIS is described in Article of Management Information Systems To Help Managers For Providing Decision Making In an Organization. This research explains that MIS provides accurate and timely information needed to facilitate decision-making processes and enable effective planning, control and operational organization[2]. Another research on MIS utilization is the research described in the article of Design of Information Management System of Municipal Engineering which explains that the design of MIS platform can be a good planning for development of management process, to improve management efficiency by utilizing information technology to achieve paperless organizational workflow. The impact of MIS utilization not only improves work efficiency, it can also be used to monitor and supervise work[3].

\section{Methodology}

\section{A. Objects and Locations of Research}

This research was conducted by designing management information system of monitoring and inspecting the implementation of universities. This research was located in Coordination of Private Higher Education Region XIV of Papua and West Papua in Biak City.

\section{B. Technique of Data Collection}

The technique of data collection used in this research include observation, interview and literature study. Observation is one of the techniques of gathering facts/data to study the on-going system. The process of direct observation was conducted to see the data management system of the infringement of universities and management of monitoring and inspecting the implementation of universities conducted by EKA Team in Coordination of Private Higher Education Region XIV of Papua and West Papua. Interview is a communication process with Coordination of Private Higher Education personnels such as Coordinator, Executive Secretary and staff to know the needs and feasibility of the designed system. The literature study was conducted after observation and interviews to find supporting references such as books and scientific journals related to the design of the MIS.

\section{Need Analysis}

Needs analysis aims to obtain data and information system needs to be designed. From the results of observations and interviews that have been done, the needs of the MIS of monitoring and inspecting the implementation of higher education, are: 1) assist the management of universities infringement data, 2) support the management of monitoring and inspection of universities infringement, starting from scheduling to the report of inspection result and recommendation; 3 ) information resulted is information of universities infringement, schedule of monitoring and inspection, report of inspection result and recommendation and also information and input for Coordination of Private Higher Education and Ministry in mapping of institutional quality of higher education.

\section{System Design}

In this research, the design of the MIS for monitoring and inspecting the implementation of universities applied Waterfall method. Waterfall method is one of software development methods that describe a systematic and sequential development approach. Stages of design using this method is very organized because the stages of work done sequentially where each stage is interconnected with each other, so the quality of system design depends on the completion of each stage of works that must be done well. Stages of system design using waterfall method consists of planning, modelling, construction, as well as delivery of systems/software to the user (deployment), which ends with sustainable support to the system.[4], [5].

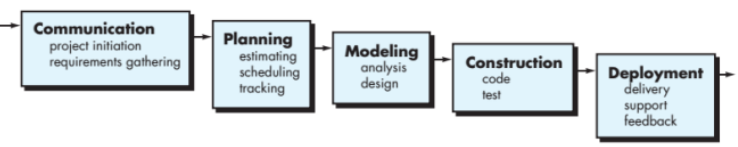

Fig 1:. Waterfall Method

The design of management information system for the inspection of alleged infringement of universities in this research using waterfall method consists of several stages, which are:

a. Communication 
Communication is the first stage of system design that includes activities to build a good and effective communication aiming to know the functional needs of the system to be designed. Communication stage is done through coordination activities about the research and interviews with the personnels of Coordination of Private Higher Education Region XIV such as Coordinator, Secretary and staff of Coordination of Private Higher Education.

\section{b. Planning}

Planning is the management stage for research activities including system design work up to the implementation of the system. In this research, the research planning includes roadmap and details of work arranged as follows:

Table 1:. Research Planning

\begin{tabular}{|c|c|c|}
\hline No & Stages & Detail of Activities \\
\hline 1. & $\begin{array}{l}\text { Data Collec- } \\
\text { tion }\end{array}$ & $\begin{array}{l}\text { - Direct observation to Coordination of Private } \\
\text { Higher Education } \\
\text { - Interview with Coordinator, Secretary and } \\
\text { Staff of Coordination of Private Higher Edu- } \\
\text { cation } \\
\text { - Studying data collection system and the in- } \\
\text { spection of universities infringement }\end{array}$ \\
\hline 2. & $\begin{array}{l}\text { Need Analy- } \\
\text { sis }\end{array}$ & $\begin{array}{l}\text { - Need analysis system } \\
\text { - Analysis of database } \\
\text { - Analysis of previous system work procedures }\end{array}$ \\
\hline 3. & $\begin{array}{l}\text { System De- } \\
\text { sign }\end{array}$ & $\begin{array}{l}\text { - Modeling with UML diagrams } \\
\text { - Conceptual data modeling } \\
\text { - System Design } \\
\text { - } \text { Testing and Implementation of the system }\end{array}$ \\
\hline 4. & Report & $\begin{array}{l}\text { - Data Analysis } \\
\text { - Analysis of System procedure } \\
\text { - Reporting }\end{array}$ \\
\hline
\end{tabular}

Research planning for the design of MIS for monitoring and inspecting the implementation of universities started from communication activities conducted with Coordination of Private Higher Education for coordination/permission of the research implementation. The next activity is to conduct direct observations to the field to identify data/facts on the on-going system and conduct interviews with Coordination of Private Higher Education personnels. The results of observation and interview are used to perform problem analysis and literature study which is to look for research-related references that support research planning. The need analysis activities include analysis for system needs, system database, and working system procedures designed. After knowing the functional requirements of the system, system modelling process can be done to describe the design model of the system that is with the UML diagram model approach. The next stage is the design of systems starting from the design of system interfaces to the design of functions based on system work. The design results are then tested to determine whether the system is running well or not until the system is implemented.

\section{c. Modeling}

Modeling is the stage of system requirement analysis that describes system design models. The system design model in this research was illustrated by using UML diagrams. UML is a widely used tool for abstracting an object-based system or software. UML can also simplify the development of sustainable software because every stage of the system development process is documented.

MIS design for monitoring and inspecting the implementation of higher education using UML modelling which includes use case diagram and activity diagram.

1. Use Case Diagram

One of important diagrams of UML used to illustrate the requirements of a system is a use case diagram, which visually illustrates the context of the interaction between the actor and the system. Each use case specifies the behavior specification (functionality) of the system being described which is required by the actor to fulfill its purpose.[6], [7], [8]. Use case diagram is a model for behavior of information system to be designed [9], [10].
To get an overview of the interaction between the user and the system on the MIS of monitoring and inspecting the implementation of higher education, then it is modeled by the use case diagram which is shown in detail in figure 2.

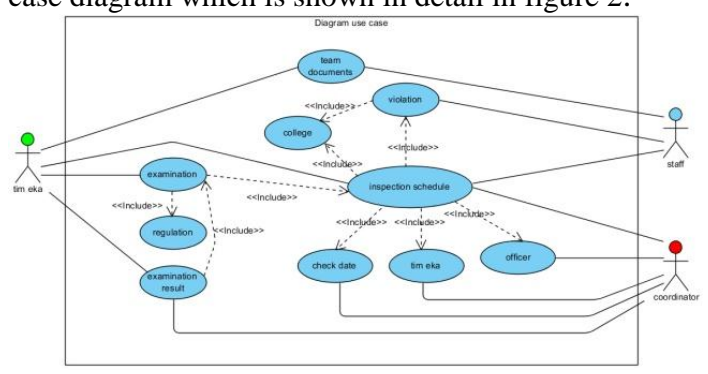

Fig 2:. Use Case Diagram

\section{Activity diagram}

Activity diagram is a diagram depicting workflow or activity of a system or business process [9]. This diagram is dynamic in modelling functions within a system and it puts pressure on the flow of control between objects. Activity diagram of MIS in monitoring and inspecting the implementation of universities consists of activity diagram of Coordination of Private Higher Education Staff, Coordination of Private Higher Education Coordinator and EKA Team as shown in figure. 3, 4 and 5.

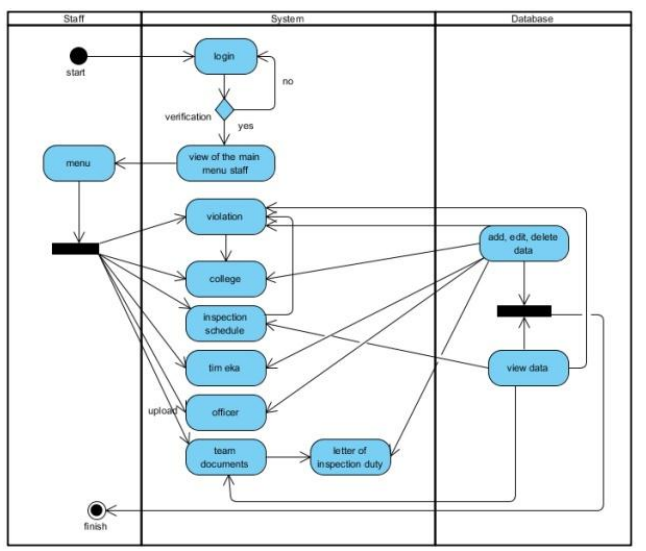

Fig 3:. Activity Diagram of Coordination of Private Higher Education Staff

The activity diagram in figure 3 describes the Staff as an administrator who has access to system data management, before entering to the system, the staff must login; if the login is successful then the system will display the main menu consisting of infringement menu, universities, EKA team, Coordination of Private Higher Education staff, inspection schedule, and EKA Team document. In the management information system, the inspection of Universities' alleged infringement, the staff is assigned to conducting data collection on universities infringement, and then the staff compile the inspection schedule of the universities based on data universities infringement. Staff should also upload EKA Team documents into the system to become the inspection documents at the universities.

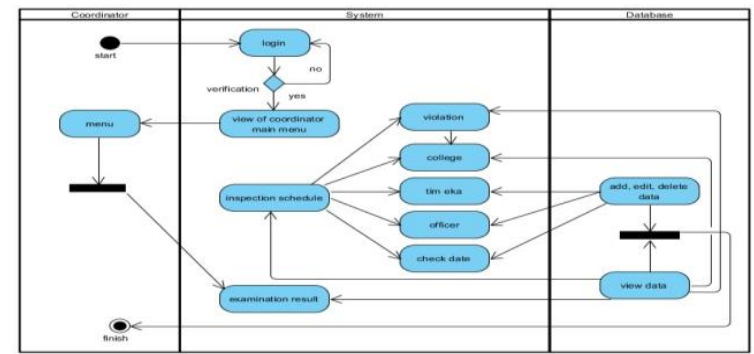

Fig 4. Activity Diagram of the Coordinator

Activity diagram of Coordination of Private Higher Education Coordinator in figure 4, explains that the Coordinator as one of the users 
who has access in accordance with the roles and duties in the system. In the management information system of the inspection of universities infringement, the Coordinator has a role as policy maker in the implementation of inspection including determining the inspection schedule, EKA Team, Coordination of Private Higher Education staff, and execution date of the activity. Implementation of infringement inspection of the universities can be directly monitored by the Coordinator, in which the main page coordinator displays report of universities infringement data, the report of the inspection include the Minutes of the Inspection and inspection result against the universities.

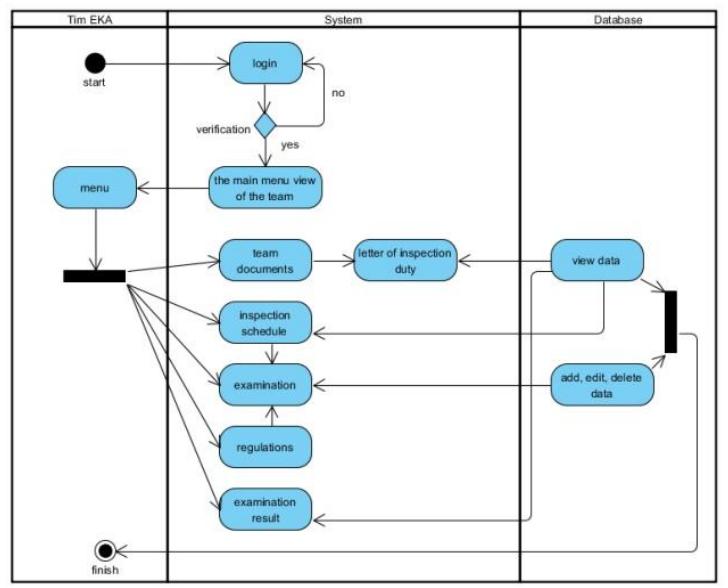

Fig 5.: Activity Diagram of EKA team

In figure 5, the EKA Team activity diagram illustrates the team activity in the information system of the inspection of universities infringement. The EKA team has the duty and role to perform the inspection based on data of universities infringement. Prior to the inspection, the EKA Team shall have a Letter of Assignment document to be presented at the time of inspection. Based on the data on the inspection schedule, the EKA Team selects the universities infringement data to conduct an inspection by looking at the type of infringement committed with the item of infringement in the regulation. The EKA team provides recommendations and conclusions about the infringement committed and administrative sanctions imposed according to the regulations. The inspection result is displayed on the report of the inspection results that can be seen by the EKA Team.

\section{Conceptual Data Model}

The conceptual data model is a data model used to define the level of data abstraction, entity relations or concepts that represent data from problem domains. This model describes the entity's characteristic details (such as attributes, data types and primary keys) [11]. Model of MIS data for monitoring and inspecting the implementation of universities can be seen in figure 6 .

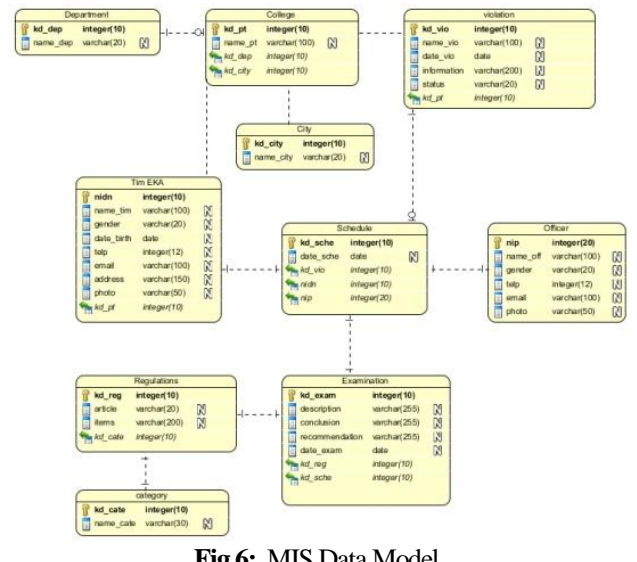

d. Construction
Construction is the stage of program coding for system design. Before the design results are implemented, the system must go through the testing stages. System testing is the stage before the implementation of system design results that aims to test every system functions or procedures to ensure the system is running and functioning properly. MIS testing for the monitoring and inspection of the implementation of universities in this research applied black-box testing method, with testing technique of use case testing. Use case testing aims to test the function of each use case that describes the functional requirements of the system based on the user's perspective.

MIS designed has 3 users who each have a main page system with menus available based on the tasks and functions of each user. All menu functions and procedures in the system go through testing, ranging from collecting infringement data, scheduling by the staffing, inspection of universities infringement based on infringement data by the regulation from EKA Team, and monitoring the inspection, and seeing the results of inspection against the universities by the Coordinator. Test results on all system functions when running well will get valid status.

Table 2. Use Case Testing Results

\begin{tabular}{|c|l|c|}
\hline No & \multicolumn{1}{|c|}{ Functions } & Status \\
\hline 1 & Staff recorded universities infringement & Valid \\
\hline 2 & Staff compiled the schedule & Valid \\
\hline 3 & Staff selected the universities infringement & Valid \\
\hline 4 & Staff selected EKA team & Valid \\
\hline 5 & $\begin{array}{l}\text { Staff selected Coordination of Private Higher } \\
\text { Education Officers }\end{array}$ & Valid \\
\hline 6 & Staff uploaded EKA Team documents & Valid \\
\hline 7 & Coordinator determined the inspection schedule & Valid \\
\hline 8 & Coordinator determined the EKA Team & Valid \\
\hline 9 & $\begin{array}{l}\text { Coordinator determined the Coordination of } \\
\text { Private Higher Education Officer }\end{array}$ & Valid \\
\hline 10 & Coordinator determines the date of inspection & Valid \\
\hline 11 & Coordinator saw the results of the inspection & Valid \\
\hline 12 & EKA team downloaded Team documents & Valid \\
\hline 13 & EKA team overviewed at the schedule & Valid \\
\hline 14 & EKA team filled out the inspection forms & Valid \\
\hline 15 & EKA team chose the universities infringement & Valid \\
\hline 16 & EKA team selected the rules & Valid \\
\hline 17 & $\begin{array}{l}\text { EKA team overviewed the results of the inspec- } \\
\text { tion }\end{array}$ & Valid \\
\hline & & \\
\hline
\end{tabular}

\section{Results and Discussion}

This research resulted in MIS which supports and assist management of monitoring and inspecting the implementation of universities (dalwasbin) in Coordination of Private Higher Education Region XIV Papua and West Papua. MIS for monitoring and inspecting the universities is designed to have three users of the system consisting of Coordination of Private Higher Education Staff, Koodinator, and EKA Team. Each user of the system has a main display with the menus based on their respective roles and duties. To access the system, users must login with their username and password.

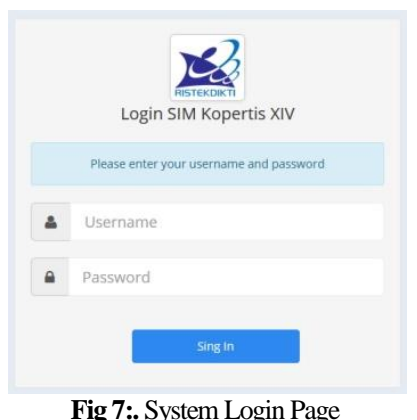

Fig 7:. System Login Page

Figure 7 shows the login page for the user on MIS for monitoring and inspecting the implementation of higher education. The login 
process is done by entering username and password. If successful then the system displays the main menu page of the user who logins. In this system, the user who serves as the administrator who manages the data management or monitoring the universities inspection is Coordination of Private Higher Education Staff. The main page display of Coordination of Private Higher Education Staff administrator can be seen in figure 8 .

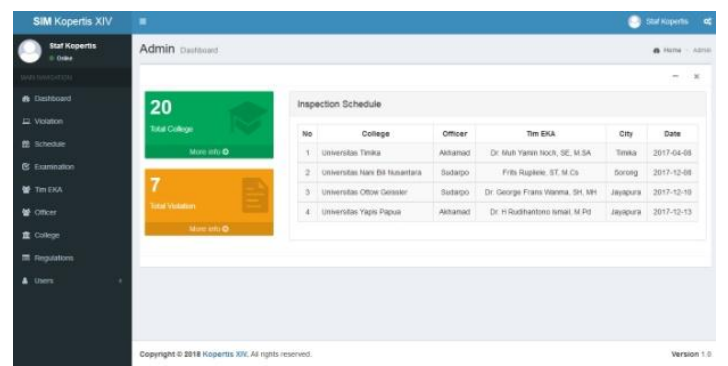

Fig 8:. Main page of Coordination of Private Higher Education Staff

Figure 8 above is the Coordination of Private Higher Education Staff page. This page contains a menu of infringement data, schedule of monitoring or inspection of universities, university inspection data, EKA Team data, Coordination of Private Higher Education Officer data, universities data, regulatory data and user/system user management data. Coordination of Private Higher Education staff has a duty as the administrator to manage data which includes adding, editing, and deleting the data. For monitoring the infringement inspection of universities, staff is assigned to record infringement based on evalution result of universities academic performance by Coordination of Private Higher Education if found indication of alleged violation. The infringement data of universities can be seen in Fig. 9. After recording the infringement data, staff coordinate with Coordinator Coordination of Private Higher Education to arrange inspection schedule against the universities.

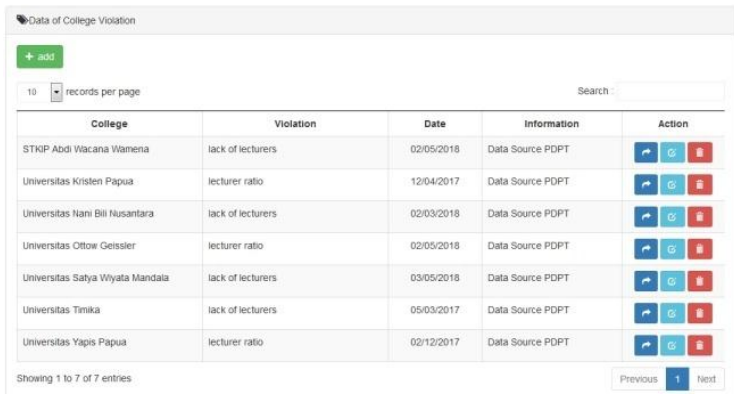

Fig 9:. Data Universities Infringement

In figure 9 , the system provides a data-added button to a schedule that serves to add selected data of university infringement into the inspection schedule. The system automatically adds the infringement data of the university to the inspection schedule form that can be seen in Fig. 10. In the preparing for the schedule, the staff must select the Officer and the EKA Team on the form of filling the schedule and then select the purpose of inspection based on universities' place of origin. Coordination of Private Higher Education staff only compile schedules of infringement, determination of officers, EKA team, and date of inspection conducted by Coordination of Private Higher Education Coordinator.

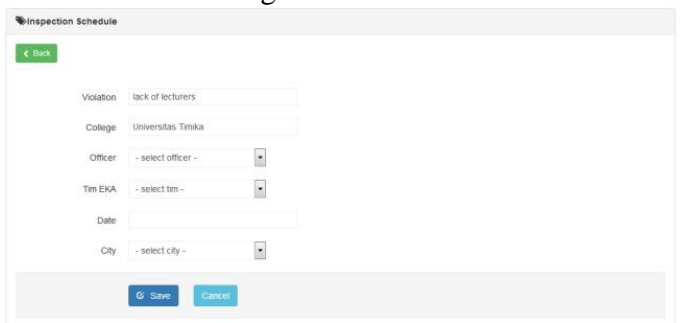

Fig 10:. Form of Filling Schedule

A. Inspection of Universities Infringement

The inspection of universiteis infringement was conducted based on the result of Coordination of Private Higher Education evaluation meeting with EKA Team regarding the finding of universities alleged infringement. Infringement data and inspection schedule on the system is inputted by Coordination of Private Higher Education staff and can be seen by each EKA Team. Each Team has permissions to log into the system. The main system display for the EKA Team can be seen in figure 11 .

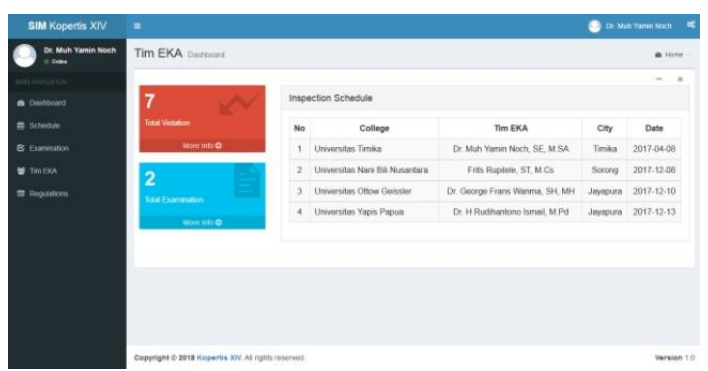

Fig 11:. Main Page of EKA Team

Figure 11 shows the main page of the EKA Team containing the inspection schedule of the universities, the total data of infringement, the inspection data, the EKA Team data covering team membership data and team documents, such as the Letter of Assignment and the Decision Letter of the EKA Team formation, the data of regulation containing clauses, paragraphs and items of assignment based on Permenristekdikti Number 100 of 2016 and data report in the form of Minutes of Inspection and inspection results.

The process of inspecting the universities infringement was conducted by EKA team which is by selecting the infringement data of universities on the schedule; the system automatically displays the inspection form containing infringements committed by the universities, the clauses, paragarphs and items of infringement selected under the regulation, description of infringement, conclusions and recommendations to Coordination of Private Higher Education regarding the infringement committed by universities. The input result of the inspection data will appear on the menu of inspection results, where the inspection data that appears on the system only the one inputted by the account of Team EKA who did login. The collection of infringement data can be seen in figure 12 and figure 13 .

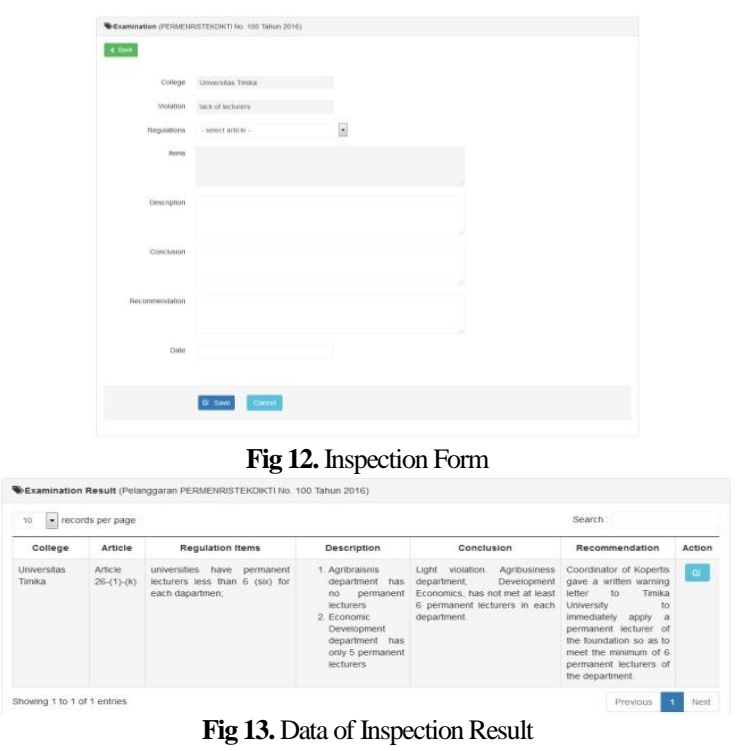


The results of the EKA Team inspections on all universities that commit infringement based on schedule will appear on the main page of Coordination of Private Higher Education Coordinator. The coordinator will only login to the system to see the results of the monitoring and inspection conducted by EKA Team. On the Coordinator's page there are the number of universities inspection results, total number of infringements committed by the universities and universities data in Coordination of Private Higher Education Region XIV. This page also contains a menu of complete infringement data, inspection schedules, inspection results and detailed report of inspection activities conducted by the EKA Team. The schedule menu contains schedule data that have been prepared by Coordination of Private Higher Education staff. The coordinator shall edit the schedule data to determine and select the EKA Team, Coordination of Private Higher Education Officers, and the date of inspection.

\section{Conclusion}

Based on the results of analysis and discussion in the MIS design, it can be concluded that the problems in the data management of universities infringement, management of monitoring and inspectin of the universities which includes planning, scheduling, preparation of documents, delivery of information up to reports of infringement inspections of universities are still run manually. MIS designed in this research is a web-based one so it becomes a solution for geographical problem of the universities that spread in island areas. MIS generates a system that can support the management of monitoring and inspections on the integrated and centralized implementation of Higher Education and generates a report on the inspection data of universities which becomes the input and information for Coordination of Private Higher Education and the ministry in mapping the quality of institutional Higher education. MIS has 3 (three) users having duties and roles in the management of monitoring and inspection of universities infringement which includes staff whose duty is as the administrator who manages the infringement data of the universities until manages the schedule preparation, EKA Team who becomes the inspectors in inspecting the universities infringement, and the coordinator who is the policy maker in selecting the team, officers, and the execution date of monitoring and inspection the universities.

\section{References}

[1] A. S. Ahmar et al., "Lecturers' understanding on indexing databases of SINTA, DOAJ, Google Scholar, SCOPUS, and Web of Science: A study of Indonesians," in Journal of Physics: Conference Series, 2018, vol. 954

[2] Al-mamary Y.H, Shamsuddin A, and Aziati N, "The Impact of Management Information Systems Adoption in Managerial Decision Making: A Review," Management Information Systems," Manag. Inf. Syst., vol. 8, no. 4, pp. 010-017, 2013.

[3] Dong B, "Design of information management system of municipal engineering," in 4th Int. Conf. Comput. Des. Manuf. Model. Simulation, CDMMS2014, 2014, pp. 449-453.

[4] Presman R.S and Maxim B.R, Software Engineering A Practitioner's Approach, 8th ed. New York: McGraw-Hill Education, 2015.

[5] F. G. J. Rupilele, "Design of Management Information System for Church service Member, Baptism, and Web-Based Marriage ( Case Study: Gekari Lembah Pujian Sorong City),” J. Teknol. Inf. dan Ilmu Komput., vol. 5, no. 2, pp. 144-152, 2018.

[6] Kurniawan T.A, "Use Case Modeling (UML): Evaluation Of Some Mistakes In Practice," J. Inf. Technol. Comput. Sci., vol. 5, no. 1, pp. $77-86,2018$

[7] C. Larman, Applying UML and Patterns: An Introduction to Object-Oriented Analysis and Design and Iterative Development. 2004.

[8] D. N. Jutla, P. Bodorik, and S. Ali, "Engineering privacy for big data apps with the unified modeling language," in Proceedings 2013 IEEE International Congress on Big Data, BigData 2013, 2013.

[9] A. Hendini, "Pemodelan UML Sistem Informasi Monitoring Penjualan dan Stok Barang,” J. Khatulistiwa Inform., 2016.
[10] H. Oinas-Kukkonen and M. Harjumaa, "Persuasive systems design: Key issues, process model, and system features," Commun. Assoc. Inf. Syst., 2009.

[11] Riberio A, Silva A, and Rodrigues A, "Data Modeling and Data Analytics: A Survey from a Big Data Perspective," J. Softw. Eng. Appl., vol. 8, no. 12, pp. 617-634, 2015. 